\title{
Arginine and the immune system
}

\author{
L. Tomás-Cobos, R. Miñambres, A. Rodrigo, M. Navarro and D. Tomás \\ Ainia Technological Centre, Parque Tecnológico de Valencia, c Benjamín Franklin 5-11, E 46980 Paterna, Valencia, Spain
}

L-Arginine ( $\arg$ ) has been classified as a semi-essential amino acid. In addition to participating in protein synthesis, L-arg has been shown to be a powerful mediator of multiple biological processes, including the release of several hormones, collagen synthesis during wound healing, antitumour activity and immune cell responses. L-Arg is metabolized in macrophages, endothelial cells, hepatocytes, kidneys cells and certain tumour cells by three enzymic pathways: inducible NO synthase (iNOS); arginase I; arginase II. In macrophages L-arg is metabolized by iNOS to produce citrulline and niticoxide, which is one of the principal cytotoxic mechanisms in these cells ${ }^{(1)}$. The availability of L-arg to modulate the immune system has lead to the this amino acid being considered to be an immunonutrient ${ }^{(2)}$.

The almond (Prunus amygdalus) is a nut with a high energy and nutritional value. The main components are vitamin E, unsaturated fatty acids, fibre and a high proportion of arg-rich protein ${ }^{(3)}$. The aim of the present study was to investigate the effects of almond, as an arg-rich food, on the immune system. Thus, NO production and genes encoding pro-inflammatory mediators such as cyclooxygenase-2 (COX-2), iNOS and TNF $\alpha$ were evaluated in a macrophage cell line of Raw 264.7 cells to test the effect of almond foods in the form of almonds or a commercial almond cream (an almond-based product containing (g/kg): fat 177, protein 70, carbohydrate 360, water 370).

Based on the bioavailability of almonds in vivo, the almond foods were subjected to two pre-treatment procedures: (1) enzymic treatment (trypsin and proteinase K); (2) simulated digestion (gastric digestion with pepsin and intestinal digestion with a pancreatinbiliary extract). Raw 264.7 cells were treated with the pre-treated or non-pre-treated almond foods. As a positive control cells were stimulated with lipopolysaccharide (LPS) and L-arg. After $6 \mathrm{~h}$ of treatment iNOS, TNF $\alpha$ and COX-2 gene expression were analysed by RT-PCR ( $\beta$-actin and $18 \mathrm{~S}$ genes were used as an internal control) and after $24 \mathrm{~h}$ of treatment NO levels were determined using the Griess reaction $^{(4)}$.

The data indicated that NO production was increased in cells treated with almond foods when compared with untreated cells. NO production by cells stimulated with almonds was decreased in presence of iNOS inhibitor $(1400 \mathrm{~W})^{(5)}$. The production of NO requires a higher concentration of digested samples than enzymic pre-treated samples. iNOS, TNF $\alpha$ and COX-2 gene expression was induced by the almond product, although higher levels were found in LPS-induced cells (positive control).
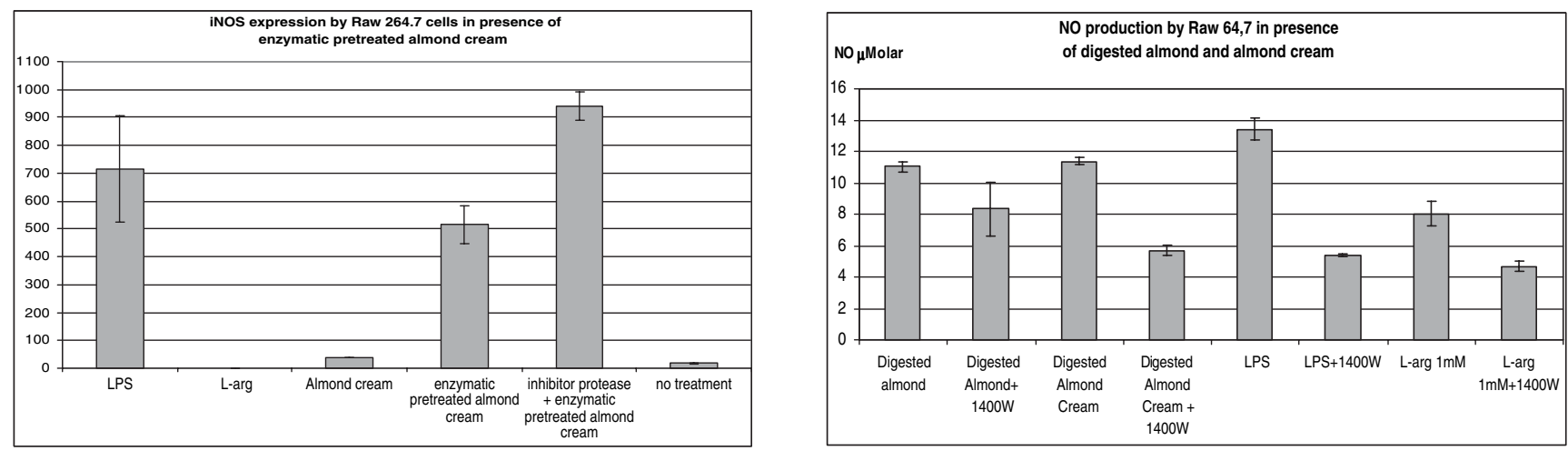

In conclusion, these preliminary results suggest that almonds can stimulate the activity of the macrophages in Raw 264.7 cells, and so stimulate the immune system. Thus, almonds could be considered to be an immunomodulator ${ }^{\text {(6) }}$. However, further investigation is needed to establish the concentration at which almonds are immunomodulatory in vivo.

1. Rodriguez PC, Zea AH, Desalvo J et al. (2003) J Immunol 17, 1232-1239.

2. Grimble RF (2001) Proc Nutr Soc 60, 389-397.

3. Mataix J, Mañas M, Llopis J \& Martinez de Victoria E (1998) Tabla de Composición de Alimentos Españoles (Spanish Food Composition Tables), 4th ed. Granada, Spain: Instituto de Nutrición y Tecnología de Alimentos.

4. Kolb JP, Paul-Eugene N, Damais C, Yamaoka K, Drapier JC \& Dugas B, (1994) J Biol Chem 269, 9811-9816.

5. Garvey EP, Oplinger JA, Furfine ES et al. (1997) J Biol Chem 272, 4959-4963.

6. Efron DT \& Barbul A (2000) Nutrition 16, 73-74. 